\title{
Nanoparticles Effects on Performance of Horseradish Peroxidase Biosensor
}

\section{Saghafi $E^{1}$ and Farahbakhsh $A^{2 *}$}

${ }^{1}$ Department of Chemical Engineering, Shahrood Branch, Islamic Azad University, Shahrood, Iran

${ }^{2}$ Department of Chemical Engineering, Quchan Branch, Islamic Azad University, Quchan, Iran

\begin{abstract}
The immobilization of horseradish peroxidase (HRP) enzyme causes protections on catalytic activities in determination of $\mathrm{H}_{2} \mathrm{O}_{2}$. The rate of electron transfer from redox enzyme onto the electrode surface is an important topic in bioelectrochemistry that could improve more the function of HRP biosensor by means of increasing electrode conductivity. Referring to this basis, effect of various nanoparticles are evaluated and compared with each other on the operation promotion in this review and Glassy Carbon Electrode (GCE) is utilized as a main foundation on immobilization of nanoparticles and HRP enzyme. Electrodes have been compared by the rate of current transfer in the optimum voltage data in the presence of Carbon-coated Iron Nanoparticles (CIN), Quantum Dots (QDs), Au and Laponite/Chit nanoparticles. Consequently in the same scan rate, HRP/Au/GCE $(28 \mu \mathrm{A})$ has achieved more current which is about $94 \%$ comparing to the base electrode HRP/GCE $(1.8 \mu \mathrm{A})$.
\end{abstract}

Keywords: Biosensor; Horseradish peroxidase; Nanoparticles; Bioelectrochemistry

\section{Introduction}

During last 20 years, biosensors have been applied as useful monitoring devices in the environmental researches owing to the advantages such as minimizing the sample pretreatment, reducing cost and time of analysis, displaying sufficient sensitivity and selectivity [1]. Among various biosensors, recent attention has turned toward the inhibition based enzyme sensor, which utilize enzyme as a bioelectrocatalyst. Horseradish peroxidase (HRP) is an important enzyme, which has been studied for more than one century and can be implemented as a critical molecule model. Hydrogen peroxide analyte has been detected to characterize performance of HRP biosensor because it is not only an important by-product formed from a lot of peroxidase-catalyzed reaction but also a signal transducer molecule in food, clinical, pharmaceutical, industrial, and environmental assays [2]. Considering that the electron transmission rate has an important role in the efficiency of biosensors and these operations are carried out by the electrode, the electrode used in biosensors structure must have a high conductivity for electron transmission from reaction zone to the transducer. In new researches to achieve this goal, the nanoparticles are used to improve the conductivity, and good compatibility of electrode structure. In this paper, to increase the performance of HRP biosensor before immobilization of the enzyme to the working electrode surface, the electrode modified by different nanoparticles. A conventional three electrode system was used throughout the electrochemical experiments with a modified or bare glassy carbon electrode as working electrode, a platinum wire as auxiliary electrode, and a saturated calomel electrode (SCE) as reference electrode. The enzyme is immobilized on polymeric electrode surface by trapped immobilization method. Working electrode has been evaluated by place in the amperometric cycle with reference and auxiliary electrode. The amount of analyte is determined by the results of current rate. The impact of nanoparticles on increasing the electrode conductivity is evaluated by coated electrode with nanoparticles.

\section{Experiments}

\section{Preparation of glassy carbon electrode}

A glassy carbon electrode (GCE $0.3 \mathrm{~mm}$ in diameter) was polished with $1.0,0.3$ and $0.05 \mu \mathrm{m} \mathrm{Al}_{2} \mathrm{O}_{3}$ slurry successively followed by rinsing thoroughly with distilled water until a mirror-like surface was obtained. Then it was washed ultrasonically in nitric acid, absolute ethanol and distilled water for 1-5 min, and allowed to dry at room temperature [3-7].

\section{Preparation of enzyme solution}

HRP solution was obtained by dissolving $5.0 \mathrm{mg}$ of HRP in $1 \mathrm{ml}$ phosphate buffer solution (PBS) (7.0) [5].

\section{Enzyme immobilization}

Solution containing HRP and different nanoparticles was dropped onto the surface of a cleaned GC electrode. Nanoparticles include: iron coated with carbon (CIN), QD, AUNPs-SF and laponite. Each solution after all, is put in condition of room temperature or refrigerator for a period of time required to get dry [3-7].

\section{Result and Discussion}

According to figure 1, the difference in current rate between GCE and HRP/GCE is about 70\%. This result shows the efficiency reduction of binding HRP to the GCE electrode. The nanoparticles are added to the HRP/GCE electrode to increase reduction.

Figures 2-5 show that the current rate is increased about $74.3 \%$, $40 \%, 94 \%$ and $76 \%$ by adding CIN, QDs, AUNPS -SF and Laponite to the HRP/GCE electrode respectfully. In order to compare the effect of nanoparticles on the electrode performance, the QD/HRP/GCE efficiency is increased about $40 \%$ to compare with the HRP/GCE. The best performance of biosensor is achieved for the gold nanoparticle with about $94 \%$ of efficiency. It comes out that however implementing different nanoparticles in the structure of the electrode can increase its

*Corresponding author: Farahbakhsh A, Department of Chemica Engineering, Quchan Branch, Islamic Azad University, Quchan, Iran, E-mail: Afshin.farahbakhsh@gmail.com

Received January 16, 2013; Accepted May 14, 2013; Published May 16, 2013

Citation: Saghafi E, Farahbakhsh A (2013) Nanoparticles Effects on Performance of Horseradish Peroxidase Biosensor. J Biosens Bioelectron 4: 136. doi:10.4172/2155-6210.1000136

Copyright: @ 2013 Saghafi $\mathrm{E}$, et al. This is an open-access article distributed under the terms of the Creative Commons Attribution License, which permits unrestricted use, distribution, and reproduction in any medium, provided the original author and source are credited. 
Citation: Saghafi E, Farahbakhsh A (2013) Nanoparticles Effects on Performance of Horseradish Peroxidase Biosensor. J Biosens Bioelectron 4: 136. doi:10.4172/2155-6210.1000136

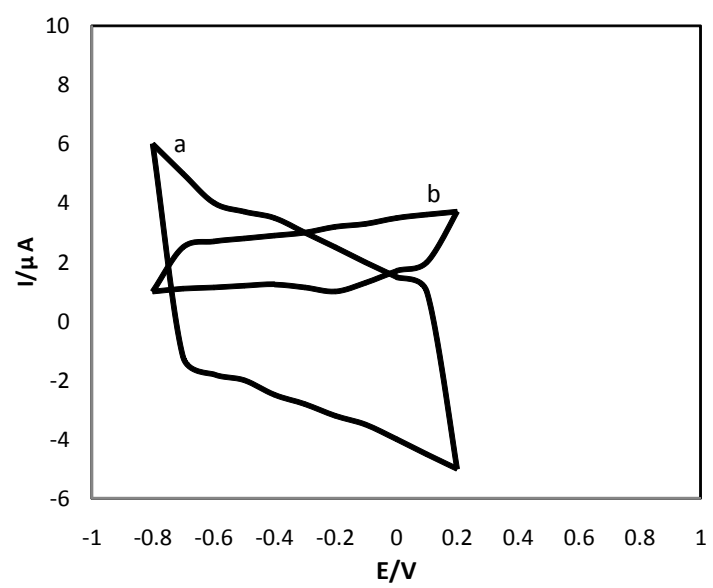

Figure 1: Cyclic voltammograms of: (a) GCE; (b) HRP/GCE.

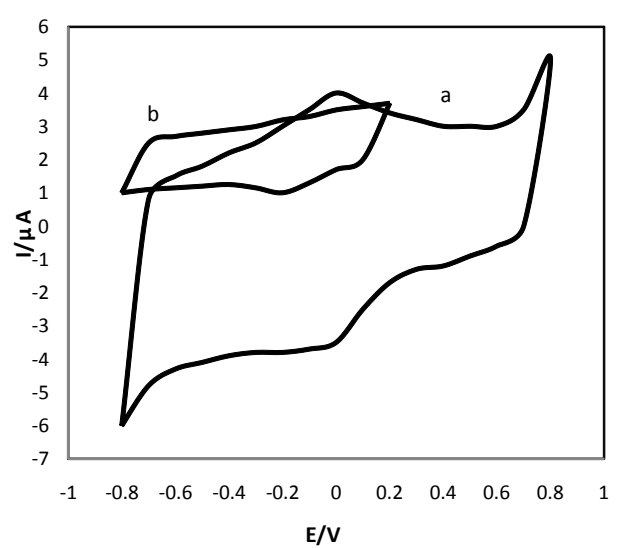

Figure 2: Cyclic voltammograms of: (a) QD+HRP/GCE; (b) HRP/GCE.

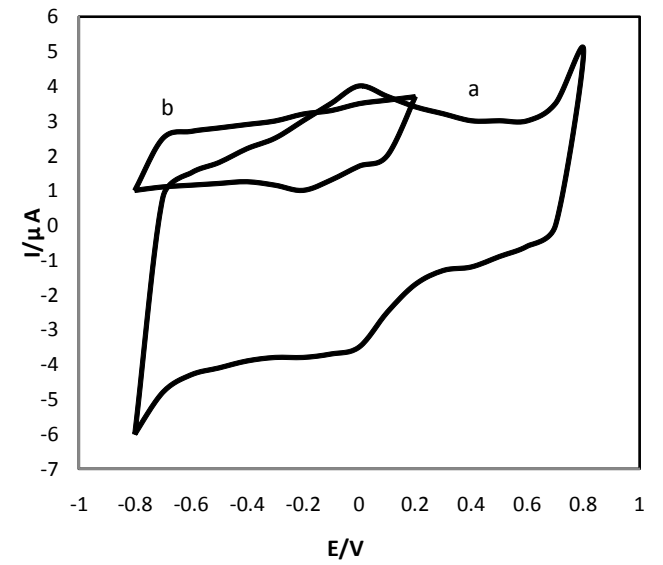

Figure 3: Cyclic voltammograms of: (a) HRP/Laponite/Chit/GCE; (b) HRP/GCE.

conductivity, but nanoparticle's type as well is effective in this improve to such a great extent. To assess these electrodes, the factors such as better conductivity, lower resistance and higher sensitivity in different range of analyte constructions should be measured and the current rate

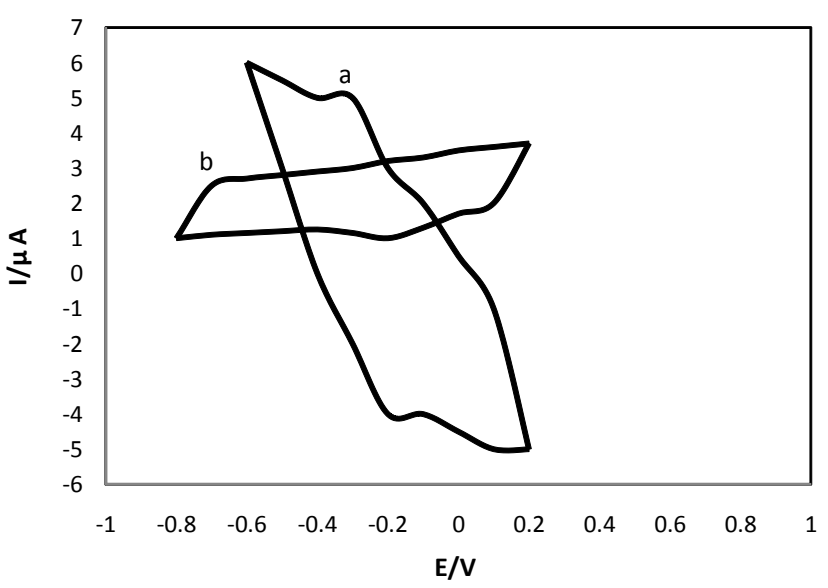

Figure 4: Cyclic voltammograms of: (a) CIN-HRP/PTH/GCE; (b) HRP/ GCE.

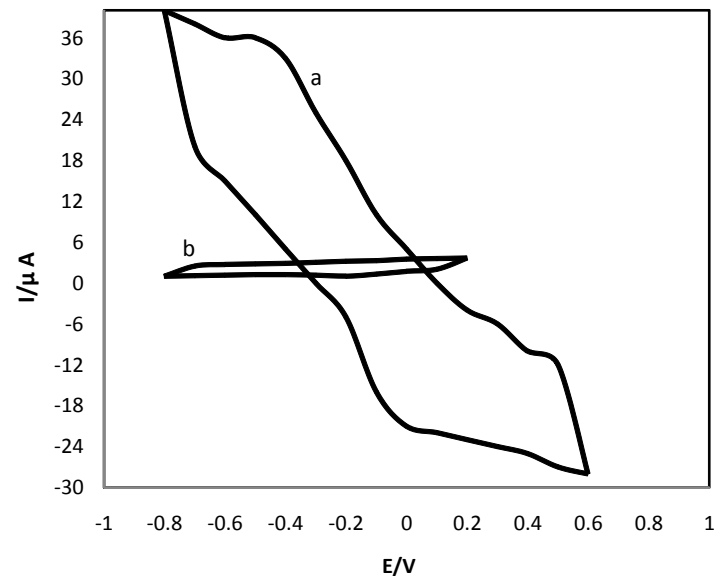

Figure 5: Cyclic voltammograms of: (a) HRP-AUNPS -SF/ GCE; (b) HRP/GCE.

\begin{tabular}{|l|l|l|l|l|l|l|}
\hline & $\begin{array}{l}\text { HRPI } \\
\text { laponite/ } \\
\text { chit/GCE }\end{array}$ & $\begin{array}{l}\text { HRP/Au/ } \\
\text { GCE }\end{array}$ & $\begin{array}{l}\text { QD/HRPI } \\
\text { GCE }\end{array}$ & $\begin{array}{l}\text { CIN/HRPI } \\
\text { PTH/GCE }\end{array}$ & $\begin{array}{l}\text { HRPI } \\
\text { GCE }\end{array}$ & GCE \\
\hline Optimum current rate & 7.5 & 28 & 3 & 7 & 1.8 & 6 \\
\hline Optimum voltage & -0.1 & -0.4 & -0.2 & -0.25 & -0.2 & -0.4 \\
\hline $\begin{array}{l}\text { Percentage of } \\
\text { deference current rate } \\
\text { between electrodes } \\
\text { and GCE }\end{array}$ & $20 \%$ & $78.6 \%$ & $-50 \%$ & $14.3 \%$ & $-60 \%$ & \\
\hline
\end{tabular}

Table 1: Comparison of electrodes performance coated with different nanoparticles.

is necessary to measure these factors for which the results are illustrated in table 1 .

\section{References}

1. Yang $Y$, Yang $M$, Wang $H$, Jiang J, Shen $G$, et al. (2004) An amperometric horseradish peroxidase inhibition biosensor based on a cysteamine selfassembled monolayer for the determination of sulfides. Sensors and Actuators B: Chemical 102: 162-168.

2. Ryoo H, Kim Y, Lee J, Shin W, Myung N, et al. (2006) Immobilization of Horseradish Peroxidase to Electrochemically Deposited Gold-Nanoparticles on Carbon Electrode for Determination of $\mathrm{H}_{2} \mathrm{O}_{2}$. Bull Korean Chem Soc 27: 5

3. Lai G, Zhang H, Han De (2009) Amperometric hydrogen peroxide biosensor 
Citation: Saghafi E, Farahbakhsh A (2013) Nanoparticles Effects on Performance of Horseradish Peroxidase Biosensor. J Biosens Bioelectron 4: 136. doi: $10.4172 / 2155-6210.1000136$

based on the immobilization of horseradish peroxidase by carbon-coated iron nanoparticles in combination with chitsan and cross-linking of glutaraldehyde. Microchim Acta 165: 159-165.

4. Wang M, Sheng Q, Zhang D, He Y, Zheng J (2012) TiC nanoparticles-chitsan composite film for the direct electron transfer of myoglobin and its application in biosensing. Bioelectrochemistry 86: 46-53.

5. Wang Z, Xu Q, Wang HQ, Yang Q, Yu JH, et al. (2009) Hydrogen peroxide biosensor based on direct electron transfer of horseradish peroxidase with vapor deposited quantum dots. Sensor and Actuators B: Chemical 138: 278282
6. Yin H, Ai S, Shi W, Zhu L (2009) A novel hydrogen peroxide biosensor based on horseradish peroxidase immobilized on gold nanoparticles-silk fibroin modified glassy carbon electrode and direct electrochemistry of horseradish peroxidase. Sensor and Actuators B. Chemical 137: 747-753.

7. Shan GD, LI QB, Ding SN, Xu JQ, Cosnier S, et al. (2010) Reagentless biosensor for hydrogen peroxide based on self-assembled films of horseradish peroxidase/Laponite/Chitosan and primary investigation on the inhibitory effect by sulfide. Biosens Bioelectron 26: 536-541. 